\title{
AN EVALUATION OF A FLIPPED APPROACH TO RISK TRAINING IN THE OPERATING THEATRE
}

\section{Introduction}

Operating departments are high-risk environments in which a safety culture is fundamental to managing inherent risks. Management of risk is an integral part of the local preceptorship course for newly qualified staff. The author has provided training for the preceptorship course in an innovative way to enhance and contextualise learning within the safe environment of a classroom. The training provides information about human error theory and how this interacts with the contextual environment of the operating department, producing risky situations.

The training enables qualified practitioners to identify and react appropriately to the weak signals of risk. The signals are varied and the training provides practical information and knowledge to encourage the staff to remain risk aware, alert to situations which may lead to error, understand how they may develop and how to mitigate that risk.

\section{Safety culture}

Evidence produced in the Francis Report is littered with deficiencies in both, organisational and individual safety culture. This deficiency obscured the detection and prevention of situations which caused patient harm (Department of Health, 2013).

Front line healthcare staff are often best placed to witness and understand potentially harmful contextual issues but may be prevented from reporting for a number of 
reasons, these include; a lack of knowledge about what should be reported and why, the effect of socialisation, and psychological safety (Braithwaite et al 2010; Edmonson and Tucker, 2004).

Effective risk management relies on staff being aware of weak signals, and communicating effectively when something is wrong (Vaughan 1997). The new staff are taught about accident and error theory in order for them to understand how situations can develop, leading to error provoking situations and subsequently patient harm.

Traditionally students are lectured to, and although considered an efficient way of transmitting information, it does not create effective learning (Lochner et al, 2016). This is due to the passive role taken by students in lectures, leading to superficial learning which engenders lower order skills (Sharples et al, 2014). Within the individual space of the flipped approach, teachers provide pre-class learning material to introduce concepts that are closely related to the learning objectives that will be expanded upon in the classroom (Sharples et al, 2014). The classroom space is used for active learning to create students responsible for their own learning (Hutchings and Quinney, 2015). 


\section{Method}

The students were given a paper introducing them to the concepts of human accident theory (Reason, 2000). The paper was to be read prior to and in-preparation for the classroom session, it was made clear to them that the theory would be applied within the session.

The session commenced with a review of the theoretical concepts to ensure the student were clear on the basic principles of active and latent error, before two scenarios were given to the student.

The scenarios were based on a series of events that involved active errors, latent conditions and other human factors. The active errors were those made by staff in the operating theatre. The students categorised them according to Reason's theory (1990), rule, knowledge, skill based errors and violations. Students were able to identify latent conditions within the scenarios that provoke error, other human factors that affect human performance and the ability to raise concerns. 
The staff used two resources for problem solving. One scenario would be worked through in the group using the information gained from the paper (Reason, 2000). The second scenario was to be used with the model shown in figure 1 to make the theory tangible and less abstract. The rectangular box holds discs, which represent defences for known risks; the holes in the discs represent how defences fail.

At the end of the exercises the groups were tasked with answering the following questions about the scenarios which enabled me to assess how well the information had been applied.

1. What defences protected the patient?

2. What active error occurred?

3. What latent condition was present?

4. Was this a near miss or patient harm?

5. What should be reported?

The last question was facilitated by the use of the reporting framework used within the department. It clearly identifies situations to be reported and how this should be done, providing practical knowledge and attempts to provide psychological safety (Newman, Donohue, Eva, 2017). 


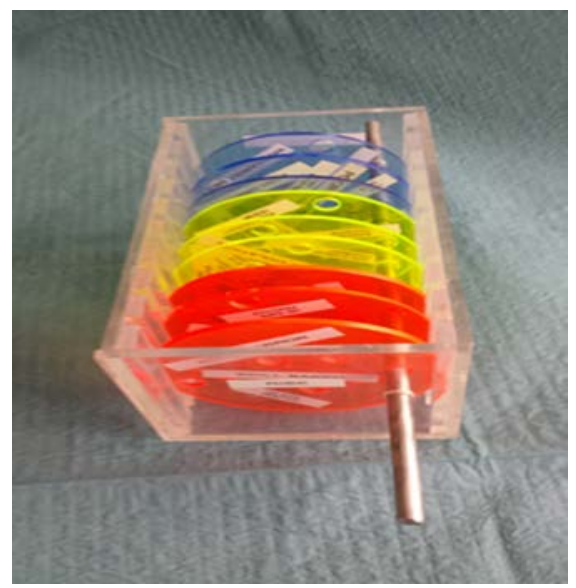

Figure 1 Model designed for classroom use

\section{Evaluation method}

Findings were elicited by structured and unstructured student feedback, response rate was $100 \%$ however the group was small (n6). Additionally, observation notes were made contemporaneously during the session and a comparison between actual sessions and evidenced based design principals were done and as a consequence, opportunities emerged (Kim et al 2014).

\section{Findings}

\section{Structured and unstructured Student feed back}

At the end of the session the six students each completed a feedback sheet. The response rate was $100 \%$ but not all question were answered by all respondents. However, the response rate was encouraging and reflected how engaged the students were within the session.

\begin{tabular}{|l|l|l|l|}
\hline Feedback question & yes & no & comments \\
\hline Did you like having pre reading material? & 5 & 1 & \\
\hline
\end{tabular}




\begin{tabular}{|c|c|c|}
\hline $\begin{array}{l}\text { Did the pre reading help you to take part in the } \\
\text { discussions? }\end{array}$ & 6 & \\
\hline $\begin{array}{l}\text { Were you able to check your understanding in } \\
\text { the classroom? }\end{array}$ & 6 & \\
\hline What issues did you clarify? & & $\begin{array}{l}\text { Some areas around } \\
\text { human factor } \\
\text { Unintentional violations }\end{array}$ \\
\hline $\begin{array}{l}\text { Did the pre reading give more time in the } \\
\text { classroom for clarification and discussion? }\end{array}$ & 5 & \\
\hline $\begin{array}{l}\text { Did you find the pre reading helped with the } \\
\text { scenario? }\end{array}$ & 4 & Some re- reading required \\
\hline Did you like the model? & 6 & \\
\hline $\begin{array}{l}\text { Mostly the paper helped me understand the } \\
\text { theory? }\end{array}$ & 1 & $\begin{array}{l}\text { Both helped one } \\
\text { reinforced the other }\end{array}$ \\
\hline $\begin{array}{l}\text { Mostly the model helped me understand the } \\
\text { theory? }\end{array}$ & 3 & \\
\hline
\end{tabular}

\section{Structured student feedback}

\begin{tabular}{|l|}
\hline Other comments \\
\hline Very interesting strategy with the model. \\
\hline The scenarios were a good way to explain a difficult and complex issue \\
\hline I want more time for the scenarios \\
\hline Highlighted culture issues maybe we go along with things \\
\hline The session was very interactive \\
\hline Very approachable and open teaching style \\
\hline Very interactive session \\
\hline
\end{tabular}




\begin{tabular}{|l|}
\hline The session was well organised \\
\hline We had lots of information to take back \\
\hline Not to be afraid to inform about issues \\
\hline
\end{tabular}

\section{Unstructured feedback from students}

The students were asked to write down at the end of the session what they thought they had learnt

\begin{tabular}{|l|}
\hline Student comments \\
\hline I have learnt that communication and team work is the best way to prevent error \\
\hline I have learnt about Human factors and the Swiss cheese model \\
environment \\
\hline How reporting a situation or accident will help minimise its future occurrence \\
\hline $\begin{array}{l}\text { It's not only personal factor, and it's the theatre environment as well. I hadn't realised } \\
\text { that before. }\end{array}$ \\
\hline The importance of safety culture \\
\hline
\end{tabular}

\section{Students' perception of learning}

\section{Observation}

The method was effective in that space was created within the session for practical application of the theory and I was able to assess the student's grasp of the theory by how they applied it. The students were engaged, and learnt from each other. During the session a Novice student was overheard saying "this scenario could never happen"! This was responded to by a more experienced student saying "I'm sure it could, that's why you have to communicate well in the operating theatre" 
The session overran by fifteen minutes as the students began to link the concepts from the theory and what should be reported.

One student said "It will make me think about reporting more"

\section{Discussion}

The flipped risk session was evidenced based and its evaluation findings were commensurate with studies into the flipped approach. The approach had created the space required for an active learning strategy to be taken which allowed time for revealing debates between the students during problem solving. The students became aware of how violations were not usually enacted by bad people, but by those who were just doing the best they could under the circumstances.

Violations are behaviours observed when the rules are known but not applied. This is not a mistake, it is intentional behaviour on the part of the practitioner (Reason 1990). The intention is often driven by contextual demands such as, the need to save time, or effort (Debono et al 2013). These behaviours are seen when staff cut corners or enact workarounds in regards to departmental procedures, collectively known as procedural drift (Snook, 2000)

Corner cutting can be seen when staff miss out steps in a workflow process, such as procedures, to save effort or time (Dixon Woods et al 2009). This would be seen in an incomplete count process or ticking a box to indicate something has been done when in reality it has not. Workarounds are different. 
Workarounds are more complex, poorly defined and often related to staff engaging in first order problem solving (Alter 2014, Tucker and Edmondson 2003). Within the operating department safety systems are implemented however non-compliant work colleagues may be "worked-around" to complete processes. There is mounting evidence that healthcare staff use workaround to enable unworkable workflow process required by safety policies and procedures by adapting them (Debono et al 2010, Clay Williams et al 2015, Nadhrah, and Michell 2013). However, adapted processes are acts of violation as they are non-compliant with agreed departmental procedure. Ad-hoc solutions, and "muddling through" can be symptoms of procedural drift (Braithwaite, Wears, Hollnagel, 2016).

Procedural drift occurs at the point of deviation from the policy or procedure and can without remedial action become normalised within work routines (Snook 2000). The deviation remains hidden within practice until revealed by fresh eyes or by a patient harm incident. The fast paced isolated environment, such as the operating theatre and cultural restraints which prevent reporting, combine to ensure the causative latent conditions, remain hidden (Kirsner and Biddle, 2012). Practice is, "work as it is done" (Clay-Williams and Braithwaite, 2016).

The session attempts to enable moral agency, combined with the practical skill of identifying and reporting contextual risk (Aveling, Parker, Dixon-Woods, 2016). The scenarios reflected real life in the operating theatre. Pre session reading gave the students the knowledge to unpick the actions of the staff within the scenarios. 
Whereas the reporting framework underlined their accountability whilst providing some psychological safety, "this is what I am expected to do".

The scenarios provided a structure for active learning, with situations from the student's everyday practice. Further structure to the activity was introduced by a set of questions to be answered by the groups by applying Reason's theory of human error and latent conditions. The project revealed that feedback did not just come from the teacher, as the more experienced students shared their knowledge. Peer and group learning within the flipped approach has been cited as a contributory success factor in the flipped approach (Lento and Blessinger 2016; Hung 2015; Jensen, Kummer and Godoy. 2015).

\section{Assessment}

The flipped approach facilitated continuous learner assessment, direct guidance and is appropriate for a diverse group of students (Flumerfelt and Green, 2013).

Similar to other studies the teacher was the guide identifying and correcting mistakes in real time (Houston and Lin, 2012, Brame 2013). This was especially helpful in that the group although small, had a diverse selection of qualified students with experience ranging from complete novice to three years in the operating theatre environment.

The flipped approach has promise for in house training as it is considered especially helpful for learning skills and behaviours. It was noted that during the session attitudes were beginning to shift (see findings) (Tan, Brainard and Larkin, 2015; Nederveld and Berge 2014). 


\section{Conclusion}

Whether the flipped approach session was sufficient to change reporting behaviour is doubtful, but attitudes were shifting in the classroom towards the intention to report. Experience of the flipped classroom was effective in providing space for action learning, assessing student learning and enabled group learning. However methods in the classroom may be ineffective within the work place without constant reinforcement strategies, leadership and supervision. It is hoped that a positive shift in safety culture will increase reporting rate as staff become aware of weak signals.

\section{References}

Alter, Steven (2014) "Theory of Workarounds," Communications of the Association for Information Systems: Vol. 34, Article 55, pp. 1041=1066.

Aveling, E. L., Parker, M., \& Dixon-Woods, M. (2016) What is the role of individual accountability in patient safety? A multi-site ethnographic study. Sociology of health \& illness, 38(2), 216-232.

Braithwaite, J., Wears, R. L., \& Hollnagel, E. (Eds.). (2016). Resilient Health Care: Reconciling Workas-Imagined and Work-as-Done.

Braithwaite J, Westbrook M, Travaglia J, Hughes C. (2010) Cultural and associated enablers of, and barriers to, adverse incident reporting. Qual Saf Health Care 2010;19:229e233.

doi:10.1136/qshc.2008.030213

Brame, C.J., (2013). Flipping the classroom. Retrieved, August, 29, p.2013.

Clay-Williams, R., Johnson, J. K., Debono, D., \& Braithwaite, J. (2015). The Path from Policy to Practice: Resilience of Everyday Work in Acute Settings. In Managing Change (pp. 26-38). Palgrave Macmillan UK.

Clay-Williams, R., \& Braithwaite, J. (2016) Realigning Work-as-Imagined and Work-as-Done: Can Training Help?. Resilient Health Care, Volume 3: Reconciling Work-as-Imagined and Work-as-Done, 153.

Debono, D. S., Greenfield, D., Travaglia, J. F., Long, J. C., Black, D., Johnson, J., \& Braithwaite, J. (2013) Nurses' workarounds in acute healthcare settings: a scoping review. BMC health services research, 13(1), 175.

Department of Health, (2013). Patients First and Foremost: The Initial Government Response to the Report of the Mid Staffordshire NHS Foundation Trust Public Inquiry. The Stationery Office. 
Dixon-Woods, M., Suokas, A., Pitchforth, E., \& Tarrant, C. (2009). An ethnographic study of classifying and accounting for risk at the sharp end of medical wards. Social Science \& Medicine, 69(3), 362-369.

Flumerfelt, S. and Green, G., (2013). Using Lean in the Flipped Classroom for At Risk Students. Educational Technology \& Society, 16(1), pp. 356-366.

Fowler, P. H., Craig, J., Fredendall, L. D., \& Damali, U. (2008) Perioperative workflow: barriers to efficiency, risks, and satisfaction. AORN journal, 87(1), 187-208.

Houston, M. and Lin, L., (2012). Humanizing the classroom by flipping the homework versus lecture equation, Society for information technology \& teacher education international conference 2012 , pp. 1177-1182.

Hung, H., (2015). Flipping the classroom for English language learners to foster active learning. Computer Assisted Language Learning, 28(1), pp. 81-96.

Hutchings, M. and Quinney, A., (2015). The Flipped Classroom, Disruptive Pedagogies, Enabling Technologies and Wicked Problems: Responding to" The Bomb in the Basement". Electronic Journal of e-Learning, 13(2), pp. 106-119.

Jensen, J.L., Kummer, T.A. and Godoy, P.D., (2015). Improvements from a flipped classroom may simply be the fruits of active learning. CBE life sciences education, 14(1), pp. ar5-08-0129.

Kim, M.K., Kim, S.M., Khera, O. and Getman, J., (2014). The experience of three flipped classrooms in an urban university: an exploration of design principles. The Internet and Higher Education, 22, pp.

37-50.

Kirsner, K. Biddle, C. (2012) Production Pressure And A Culture Of Deviance In The Insular Operating Room And The Consequences Of Their "Normalization": Have We Reached A Hooper Moment?. The Internet Journal of Law, Healthcare and Ethics. Volume 8 Number 1.

Koppel R, Wetterneck T, Telles JL, et al. (2008) Workarounds to barcode medication administration systems: their occurrences, causes, and threats to patient safety. J Am Med Inform Assoc. 15(4):408423.

Lento, C. and Blessinger, P., (2016). Promoting active learning in introductory financial accounting through the flipped classroom design. Journal of Applied Research in Higher Education, 8(1).

Lochner, L., Wieser, H., Waldboth, S. and Mischo-Kelling, M., (2016). Combining traditional anatomy lectures with e-learning activities: how do students perceive their learning experience? International journal of medical education, 7, p.69.

Nadhrah N, Michell .V, (2013). Workarounds: Risk or Benevolence for Patient Safety? In: Mitchell V, RosenornLang D, Currie W, Gulliver S (ed.) Handbook of Research on patient safety and quality care through health Informatics. United States of America. Medical Information Science Reference, p,76-103

Nederveld, A. and Berge, Z.L., (2015). Flipped learning in the workplace. Journal of Workplace Learning, 27(2), pp. 162-172.

Network, F.L., (2014). The four pillars of FLIP. Retrieved from www. flippedlearning. org/ definition. Last accessed January 2017 
Newman, A., Donohue, R., \& Eva, N. (2017). Psychological safety: A systematic review of the literature. Human Resource Management Review.

Perneger, T.V., (2005). The Swiss cheese model of safety incidents: are there holes in the metaphor? BMC health services research, 5(1), pp. 1.

Post, J.L., Deal, B. and Hermanns, M., (2015). Implementation of a flipped classroom: Nursing students' perspectives. Journal of Nursing Education and Practice, 5(6), p.25.

Reason James (1990). Human Error. Cambridge University press.

Reason , J., (2000). Human error: models and management. BMJ (Clinical research ed.), 320(7237), pp. 768-770.

Roehl, A., Reddy Y, S.L. and Shannon, G.J., (2013). The flipped classroom: An opportunity to engage millennial students through active learning. Journal of Family and Consumer Sciences, 105(2), pp. 44.

Rottellar, C. and Cain, J., (2016). Research, Perspectives, and Recommendations on Implementing the Flipped Classroom. American Journal of Pharmaceutical Education, 80(2).

Sharples, M., Adams, A., Ferguson, R., Gaved, M., McAndrew, P., Rienties, B., Weller, M. and Whitelock, D., (2014). Innovating Pedagogy 2014. Open University Innovation Report 3.Milton Keynes: The Open University.

Snook S.A. (2000). Friendly Fire: The Accidental Shootdown of U.S. Black Hawks Over Northern Iraq. Princeton U.P. New Jersey

Strayer, J.F., (2012). How learning in an inverted classroom influences cooperation, innovation and task orientation. Learning Environments Research, 15(2), pp. 171-193.

Tan, E., Brainard, A. and Larkin, G.L., (2015). Acceptability of the flipped classroom approach for inhouse teaching in emergency medicine. Emergency Medicine Australasia, 27(5), pp.453-459.

Tucker, A.L. and Edmondson, A.C., (2004). Why hospitals don't learn from failures: Organizational and psychological dynamics that inhibit system change. California management review, 45(2), pp. 55-72.

Van Vliet, E.A., Winnips, J.C. and Brouwer, N., (2015). Flipped-Class Pedagogy Enhances Student Metacognition and Collaborative-Learning Strategies in Higher Education But Effect Does Not Persist. CBE life sciences education, 14(3), pp. 10.1187/cbe.14-09-0141.

Vaughan, D., (1997). The Challenger launch decision: Risky technology, culture, and deviance at NASA. University of Chicago Press. 